\title{
Sap Flow Response to Olive Water Stress: a Comparative Study with Trunk Diameter Variations and Leaf Turgor Pressure
}

\author{
J.E. Fernández, M.V. Cuevas, C.M. Rodriguez- \\ Dominguez, A. Perez-Martin, J.M. Torres-Ruiz, S. \\ Elsayed-Farag and A. Diaz-Espejo \\ Insituto de Recursos Naturales y Agrobiología \\ Avenida de Reina Mercedes, 10 \\ 41012-Sevilla, Spain
}

\author{
M.J. Martín-Palomo \\ ETSIA, Dep. de Ciencias \\ Agroforestales, Carretera de \\ Utrera, 41013 Sevilla, Spain
}

Keywords: Olea europaea, deficit irrigation, irrigation scheduling, transpiration, trunk growth

\begin{abstract}
The aim of this work was to evaluate the potential of used sap flow (SF), trunk diameter variation (TDV) and leaf turgor (LT) sensors for assessing water stress in a 'Arbequina' hedgerow olive orchard with 1667 trees ha ${ }^{-1}$. Measurements were made in control trees irrigated to replace $100 \%$ of the crop water needs, and in trees under two regulated deficit irrigation strategies, 60RDI and 30RDI, in which irrigation replaced ca. $60 \%$ and $30 \%$ of the control, respectively. From the SF and TDV measurements we calculated the daily difference, both for tree water consumption $\left(D_{E p}\right)$ and maximum trunk diameter $\left(D_{M X T D}\right)$, between RDI trees and control trees. With the LT sensors we recorded the leaf patch output pressure $\left(P_{\mathrm{p}}\right)$, which is related to the leaf turgor pressure. Both $D_{E p}$ and $D_{M x T D}$ responded quickly and markedly to changes in water stress. The seasonal dynamics of both indices agreed with that of the stem water potential. A decrease in the reliability of $D_{E p}$ was recorded on days of highly variable atmospheric demand. The LT sensors also showed to be highly sensitive to changes on water stress. Any of the three methods have a potential as indicators for precise irrigation in hedgerow olive orchards with high plant density and low soil water-holding capacity.
\end{abstract}

\section{INTRODUCTION}

The world surface of hedgerow olive orchards (HOO) with plant densities close or over 2000 trees $^{-1}$ is ca. 100.000 ha (Rius and Lacarte, 2010). These orchards are also known as super-high-density hedgerow orchards (Vossen, 2007). In addition to the need for improving crop water productivity in HOO, plant vigour must be controlled for optimum illumination profiles on canopy walls and to keep a tree size suitable for mechanical harvesters (Gomez-del-Campo et al., 2009). Deficit irrigation (DI) contributes to the achievement of both requirements and, therefore, it is highly advisable for HOO.

Regulated deficit irrigation, RDI (Chalmers et al., 1981), is an advisable DI strategy for HOO. It consists in replacing the crop evapotranspiration $\left(\mathrm{ET}_{\mathrm{c}}\right)$ by irrigation during the phenological stages at which the crop is more sensitive to water stress, and reducing or even withholding irrigation for the rest of the cycle. A reliable monitoring of water stress in fruit tree orchards under RDI is required to avoid significant water stress levels in sensitive phenological stages, and so to ensure the crop performance in the current and future years (Connor and Fereres, 2005). Among the characteristics of a good indicator for irrigation scheduling, detailed by Fernández and Cuevas (2010) among 
others, the sensitivity and earliness becomes crucial in HOO with high plant densities, because of the possibility of sudden increases of water stress in the trees due to the reduced rootzones, i.e. to the small amounts of available water.

Some of the most promising sensors for the continuous and automatic monitoring of tree water stress are based on measurements of sap flow, SF (Fernández et al., 2008), trunk diameter variation, TDV (Fernández and Cuevas, 2010; Ortuño et al., 2010) and leaf turgor, LT (Ben-Gal et al., 2010; Fernández et al., 2011a). Our hypothesis is that either method can be used for a precise monitoring of the tree's water stress in HOO, provided a proper index, derived from the outputs of each method, is used. But very few comparative studies have been made on the advantages and shortfalls of each method. The aim of this work was to evaluate the usefulness of indices derived from SF, TDV and LT measurements as indicators of water stress in a fully productive HOO with high plant density. Results of the three methods with trees under two different RDI strategies were compared with midday stem water potential $\left(\Psi_{\text {stem }}\right)$ measurements. This work shows the performance of each indicator both for a period of increasing water stress and for a period of release from water stress.

\section{MATERIALS AND METHODS}

\section{The orchard}

The experiments were made in a $\mathrm{HOO}$ close to Seville, southwest Spain $\left(37^{\circ} 15^{\prime}\right.$ $\left.\mathrm{N},-5^{\circ} 48^{\prime} \mathrm{W}\right)$, with 4-year-old 'Arbequina' trees planted at $4 \mathrm{~m} \times 1.5 \mathrm{~m}\left(1667\right.$ trees $\left.\mathrm{ha}^{-1}\right)$. The trees rows run N-NE to S-SW. The orchard has a dual soil with a top $0.6 \mathrm{~m}$ layer (77.7\% sand, $2.2 \%$ silt and $20.1 \%$ clay) which overlaid a less porous, heavier layer $(60.9 \%$ sand, $37.1 \%$ clay and $2.0 \%$ silt). The rootzones of most trees was in the top soil layer (Fernández et al., unpublished results). That layer had a volumetric soil water $\left(\theta_{\mathrm{v}}\right)$ content of $0.181 \mathrm{~m}^{3} \mathrm{~m}^{-3}$ for field capacity (soil matric potential: $\Psi_{\mathrm{m}}=-0.03 \mathrm{MPa}$ ) and $0.089 \mathrm{~m}^{3} \mathrm{~m}^{-3}$ for the wilting point $\left(\Psi_{\mathrm{m}}=-1.5 \mathrm{MPa}\right)$. The area has a Mediterranean climate, with a mild, wet season (October to April) and a hot, dry season for the rest of the year. Yearly average precipitation $(P)$ and potential evapotranspiration $\left(\mathrm{ET}_{\mathrm{o}}\right)$ for the 2002-2010 period were $554.7 \mathrm{~mm}$ and $1542.8 \mathrm{~mm}$, respectively.

Experiments were made in 2010. From May 18 to May 31, all trees in the orchard received enough water to match the crop water requirements. From June 1, day of year (DOY) 152 to November 2 (DOY 306), two RDI treatments were established in the orchard, scaled to a total irrigation amount (IA) of $60 \%$ (60RDI) and $30 \%$ (30RDI) of $\mathrm{ET}_{\mathrm{c}}$. Water supplies in both treatments were close to crop water requirements both at the beginning of pit hardening and during the period of active oil accumulation in the fruits from late August, two periods for which olive is sensitive to water stress. Water supplies, however, were markedly reduced in midsummer, when the olive tree is less sensitive to water stress (Connor and Fereres, 2005; Fernández et al., 2011a). We used a randomized block design with four $12 \mathrm{~m} \times 16 \mathrm{~m}$ plots per treatment. Each plot contained 8 central trees surrounded by 24 border trees. All measurements were made in the central trees of each plot. We also had an additional plot, named control plot, in which the trees were daily irrigated to replace $100 \%$ of the irrigation needs (IN), calculated as IN $=\mathrm{ET}_{\mathrm{c}}-P_{\mathrm{e}}$, being $P_{\mathrm{e}}$ the effective precipitation calculated as $75 \%$ of $P$ recorded by a weather station located in the orchard. Daily values of $\mathrm{ET}_{\mathrm{c}}$ were determined with the crop coefficient approach, as explained by Fernández et al. (2011a). The irrigation system consisted of one drip line per tree row with a $2 \mathrm{~L} \mathrm{~h}^{-1}$ dripper every $0.5 \mathrm{~m}$. We used an irrigation 
controller (Agronic 2000, Sistemes Electrònics PROGRÉS, S.A., Lleida, Spain) for supplying the calculated INs. The irrigation system had one caudalimeter per treatment, to record the applied irrigation amounts (IAs).

\section{Plant measurements}

Measurements of stem water potential at midday $\left(\Psi_{\text {stem }}\right)$ were made once every two weeks during the whole irrigation season. We used a Scholander-type pressure chamber (PMS Instrument Company, Albany, Oregon, USA). For the RDI treatments we sampled one leaf per tree from two representative trees per plot $(n=8)$. In the control plot we sampled two leaves per tree from four trees in order to have the same number of replicates. The leaves, taken from the inner part of the canopy, were wrapped in aluminum foil ca. $2 \mathrm{~h}$ before the measurements.

On May 4 two Verdtech stations (Verdtech Nuevo Campo, S.A., Huelva, Spain) were installed in the orchard. The standard Verdtech sation was described by Cuevas et al. (2010). The ones we installed in the orchard had Plantsens radial dendrometers (Verdtech un Nuevo Campo S.A., Spain). We recorded TDV in a representative tree per plot, in three plots of each RDI treatment. In the control plot we instrumented three trees. The dendrometers were placed in the north side of the trunks, at about 0.3-0.4 m above ground, in locations free of scars. The stations stored $15 \mathrm{~min}$ averages of the TDV data from May 4 to November 2, 2010. We used these data to calculate the $\mathrm{D}_{\text {MXTD }}$ index, defined by Fernández et al. (2011b) as the daily difference between the RDI trees and the control trees for the maximum trunk diameter (MXTD).

From June 2 to November 2, 2010, we used heat-pulse velocity (HPV) probes (Tranzflo NZ Ltd., Palmerston North, New Zealand) to measure SF with the Tz heatpulse method (Green et al., 2003). Two sets of probes were installed in the trunk of each tree instrumented with a dendrometer. Each set had two temperature probes, located at 5 $\mathrm{mm}$ upstream and $10 \mathrm{~mm}$ downstream of a linear heater probe. Each temperature probe had four thermocouples, at $6,13,22$ and $33 \mathrm{~mm}$. Taking into account that the average trunk radius without bark was $20 \mathrm{~mm}$, the effective depths were $6,7,13$ and $18 \mathrm{~mm}$ below the cambium. One set of HPV probes faced east and the other west, and the minimum distance between the two sets was of ca. $0.1 \mathrm{~m}$. The distance between the dendrometer and the closest HPV probe was also of ca. $0.1 \mathrm{~m}$. Heat pulses $(60 \mathrm{~W}$ over 1 s) were applied once every $30 \mathrm{~min}$. We used a CR10X Campbell datalogger (Campbell Scientific Inc, North Logan, USA) both to fire the heat pulses and to record the outputs. The method was validated for olive by Fernández et al. (2006). After averaging the outputs of the two probe sets per tree, we calculated the sap flux $\left(Q, \mathrm{~L} \mathrm{~h}^{-1}\right)$ in the trunk of each instrumented tree, as well as the daily tree water consumption $\left(E_{\mathrm{p}}, \mathrm{L} \operatorname{tree}^{-1}\right.$ day $\left.^{-1}\right)$. For each RDI treatment we calculated the $\mathrm{D}_{E \mathrm{p}}$ index as the daily difference between the RDI trees and the control trees for the $E_{\mathrm{p}}$.

For the LT measurements in the RDI trees, we installed, on April 26, a ZIM probe (ZIM Plant Technology GmbH, Hennigsdorf, Germany) in each tree instrumented with TDV and SF sensors. Probes were clamped on leaves of the east side of the canopy, at about $1.5 \mathrm{~m}$ above ground. The output pressure $\left(P_{\mathrm{p}}\right)$ sensed by the probe is inversely proportional to the leaf turgor pressure $\left(P_{\mathrm{c}}\right)$ (Zimmermann et al., 2008). In the control plot we instrumented one representative tree only. The output pressure signals of the probes were collected every $5 \mathrm{~min}$ for about five months. The system associated to the ZIM probes for data recording and transmission is described in Fernández et al. (2011a). 


\section{Soil and weather measurements}

In every RDI plot we installed two access tubes for a Profile probe (Delta-T Devices Ltd, Cambridge, UK), at ca. $0.5 \mathrm{~m}$ from the tree trunk and of $0.1 \mathrm{~m}$ and $0.4 \mathrm{~m}$, respectively, from the nearest dripper. In the control plot we installed six access tubes, three at a distance of $0.1 \mathrm{~m}$ and three at a distance of $0.4 \mathrm{~m}$ from the dripper. Measurements of $\theta_{\mathrm{v}}$ were made 1-2 times per week, in each access tube. From the measured $\theta_{\mathrm{v}}$ values we derived a depth equivalent of water expressed as the level of relative extractable water, REW (Granier, 1987).

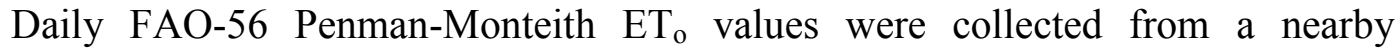
weather station belonging to the Agroclimatic Information Network of the Junta of Andalusia.

\section{Statistical analysis}

Data are given as mean \pm standard error. The effect of the irrigation treatment on $\Psi_{\text {stem }}, E_{\mathrm{p}}$, MDS and MXTD was evaluated by analysis of variance (ANOVA; separation of means with the Tukey's test; statistically significant differences at $P<0.05$; SigmaPlot 11.0, Systat Software, Inca., USA).

\section{RESULTS AND DISCUSSION}

\section{Water conditions and plant water status}

The atmospheric demand during the irrigation season was as usual in the area: the most demanding conditions occurred in July and August, while decreasing $\mathrm{ET}_{\mathrm{o}}$ values were recorded from the beginning of September onwards throughout autumn (Fig. 1A).

In the control treatment, the total IA throughout the irrigation season (Fig. 1B) amounted to $100.8 \%$ of IN. From June 1 (DOY 152) to June 22 (DOY 173), the 60RDI trees were irrigated daily with $70-80 \%$ of $\mathrm{ET}_{\mathrm{c}}$. From June 23 to August 23 (DOY 235), the 60RDI trees were irrigated twice a week only (Fig. 1B). For that period the 60RDI trees received less than one third of the INs. From August 24 (DOY 236) to October 11 (DOY 284) the 60RDI trees were irrigated daily again, with enough water to replace the INs. The 30RDI trees were irrigated daily until DOY 173. Between DOY 174 and DOY 235 they were irrigated once a week (Fig. 1B). From DOY 236 to 284, the 30RDI trees were irrigated twice a week. For the whole irrigation season the 60RDI and 30RDI treatments received $61.8 \%$ and $29.7 \%$ of IN, respectively.

In the control treatment REW values showed soil water conditions close to field capacity (Fig. 1C). In both RDI treatments REW values decreased from DOY 174, when irrigation was reduced, to DOY 235. In the 60RDI treatment the increase in irrigation from DOY 236 was enough for the REW values to recover in some two weeks. In the 30RDI trees REW values increased from DOY 236 but they did not become similar to those in the control treatment until late in the season, after the first significant rainfall events of the autumn, recorded in mid-October (Fig. 1B).

In the control plot, $\Psi_{\text {stem }}$ was usually greater than $-1.4 \mathrm{MPa}$ (Fig. 1D), a threshold value for water stress in olive trees with heavy fruit load (A. Moriana, University of Seville, personal communication). In the 60RDI trees, $\Psi_{\text {stem values were below that }}$ threshold from mid-July to the beginning of September. Similar $\Psi_{\text {stem }}$ values were recorded in the 60RDI trees and in the control trees from the beginning of September to the end of the season. In the 30RDI trees, the decrease of $\Psi_{\text {stem }}$ in July was similar to that 
in the 60RDI. In August, however, the 30RDI trees became more stressed. For the rest of the month and all throughout September $\Psi_{\text {stem }}$ values remained lower in the 30RDI trees than in the 60RDI trees. This agrees with differences between those treatments in the available soil water (Fig. 1C).

\section{Response of the three methods to water stress conditions}

The response of $\mathrm{D}_{E \mathrm{p}}, \mathrm{D}_{\mathrm{MXTD}}$ and $P_{\mathrm{p}}$ to the increasing water stress in the RDI treatments after the reduction in irrigation at the beginning of the midsummer period is shown in Fig. 2. The decrease in $\mathrm{D}_{E \mathrm{p}}$ began on DOY 174 in the 30RDI treatment, and on DOY 177 in the 60RDI treatment (Fig. 2B). This difference between treatments could be due, at least in part, to the irrigation event applied to the 60RDI trees on DOY 176 (Fig. $2 B)$. For both RDI treatments, decreasing $\mathrm{D}_{E \mathrm{p}}$ values were recorded until DOY 186. Still, some increase in the $\mathrm{D}_{E \mathrm{p}}$ values were recorded on the days in which irrigation was applied to the RDI trees were. On these days $E_{\mathrm{P}}$ in the RDI trees increased (data not shown), which led to an increase in the corresponding $\mathrm{D}_{E \mathrm{p}}$ value (Fig. $2 \mathrm{~B}$ ). The $\mathrm{D}_{\mathrm{MXTD}}$ values began to decrease 1-2 days later than the $\mathrm{D}_{E \mathrm{p}}$ values (Fig. $2 \mathrm{C}$ ), for both RDI treatments. As for $\mathrm{D}_{E \mathrm{p}}, \mathrm{D}_{\mathrm{MXTD}}$ values fluctuated according to the irrigation events of each RDI treatment. For the 60RDI trees, the $P_{\mathrm{p}}$ values showed increasing daily maximums and increasing night values from DOY 174 (Fig. 2D). According to fundamentals of the ZIM probes (Zimmermann et al., 2008), both characteristics show increasing water stress. Values of $P_{\mathrm{p}}$ decreased on the days in which irrigation was applied, showing a high sensitivity of the ZIM probes to changes on the trees water status. $P_{\mathrm{p}}$ changes were more dramatic on the 30RDI trees (Fig. 2E), which agree with the lower water supplies received by those trees (Fig. 2A). On DOY 182 we recorded the first signs of inversion in the $P_{\mathrm{p}}$ curves recorded from the 30RDI trees, and by DOY 185 the curves were fully inverted (Fig. 2E). According to Ehrenberger et al. (2011), inverse diurnal $P_{\mathrm{p}}$ curves appear when $P_{\mathrm{c}}<<<50 \mathrm{kPa}$. i.e. the leaf is significantly dehydrated. Inverse curves were reported by Ben-Gal et al. (2010) in olive trees under severe water restrictions.

Figure 3 shows the details of the $\mathrm{D}_{E \mathrm{p}}, \mathrm{D}_{\mathrm{MXTD}}$ and $P_{\mathrm{p}}$ dynamics on the days before and after the increase in irrigation from DOY 236. The $\mathrm{D}_{E \mathrm{p}}$ values fluctuated from ca. DOY 225 to 235, due to the influence of marked changes in $\mathrm{ET}_{\mathrm{o}}$ on $E_{\mathrm{p}}$. It is known that, for high available soil water conditions, $E_{\mathrm{p}}$ in olive is closely related to $\mathrm{ET}_{\mathrm{o}}$ (Fernández et al., 2001; Tognetti et al., 2009). Our results, however, show that the sudden decrease in $\mathrm{ET}_{\mathrm{o}}$ around DOY 230 (Fig. 1A) had a stronger influence in the $E_{\mathrm{p}}$ of control trees than in that of RDI trees (data not shown). This was likely due to $E_{\mathrm{p}}$ in the latter being already restricted by the reduced available water in the soil. This behaviour limited the potential of $\mathrm{D}_{E \mathrm{p}}$ as indicator for water stress, on those days of changing weather conditions. From DOY 236 , when the weather conditions were stable again, $\mathrm{D}_{E \mathrm{p}}$ slightly increased in both RDI treatments, in agreement with the increasing soil water content caused by the increases in irrigation. For the period shown in Fig. 3, values of $\mathrm{D}_{\text {MXTD }}$ were less influenced than those of $\mathrm{D}_{E \mathrm{p}}$ by the changing weather conditions. Thus, $\mathrm{D}_{\mathrm{MXTD}}$ values decreased continuously until DOY 236, except on the same day and the day after each irrigation event, as already mentioned. The tendency changed to increasing $\mathrm{D}_{\text {MXTD }}$ values immediately after the increase in irrigation from DOY 236. In the 60RDI trees, normal $P_{\mathrm{p}}$ curves, i.e. with maximum values recorded during the day and minimum values during the night, were recorded soon after the increase on irrigation from DOY 236 (Fig. 3D). Both the maximum $P_{\mathrm{p}}$ values during the day and the minimum values during the night decreased from that day on, in agreement with the water status recovery in those trees 
(Fig. 1C). In the 30RDI trees, the increase in irrigation after DOY 236 was not enough to get normal $P_{\mathrm{p}}$ curves (Fig. 3D). Once again, this is in agreement with the slow and incomplete recovery form water stress of the 30RDI trees at that time of the year (Fig. $1 C)$.

The decreasing and increasing trends both of $\mathrm{D}_{E \mathrm{p}}$ and $\mathrm{D}_{\mathrm{MXTD}}$ shown in Figs. 2 and 3 agree with those of $\Psi_{\text {stem }}$ (Fig. 1D). The same can be said for $P_{\mathrm{p}}$. By the time the first inverse diurnal $P_{\mathrm{p}}$ curves were recorded, $\Psi_{\text {stem }}$ was ca. $-1.70 \pm 0.16 \mathrm{MPa}$. Inverse $P_{\mathrm{p}}$ curves were recorded during the most stressing midsummer period, in trees of both RDI treatments. After the recovery from DOY 236, the inverse $P_{\mathrm{p}}$ curves disappear when the trees show $\Psi_{\text {stem }}$ values of ca. $-1.6 \pm 0.06 \mathrm{MPa}$.

Our results show a satisfactory response of $\mathrm{D}_{E \mathrm{p}}$ and $\mathrm{D}_{\mathrm{MXTD}}$ as indices to monitor changes in the plant water consumption and water stress of the trees of both RDI treatments as compared to those of the control treatment. The commented limitations of $\mathrm{D}_{E \mathrm{p}}$ as a water-stress indicator, on days of sudden changes in $\mathrm{ET}_{0}$, may have little impact, since in most areas where the olive tree is cropped weather conditions during the irrigation season are usually stable. The usefulness of the $\mathrm{D}_{E \mathrm{p}}$ index to monitor the influence of DI on the olive tree water consumption was first reported by Fernández et al. (2011b). They observed a limited usefulness of the $\mathrm{D}_{E \mathrm{p}}$ index to monitor the onset of water stress, caused by the high capacity of the olive tree to take up water from drying soils. But they worked with old 'Manzanilla' olive trees with large rhizospheres, planted in a soil with medium-to-high water holding capacity. In our case the trees had much smaller root systems, and the water-holding capacity of our experimental soil was smaller. For our conditions, therefore, the buffer capacity of the soils was much smaller.

The earliness of the $\mathrm{D}_{\text {MXTD }}$ index was similar to that of $\mathrm{D}_{E \mathrm{p}}$ for detecting both the onset of water stress in both RDI treatments soon after the reduction in irrigation from DOY 174 (Fig. 2B and 2C) and the release from water stress after the increase in irrigation from DOY 236 (Fig. 3B and 3C). Contrary to $\mathrm{D}_{E \mathrm{p}}, \mathrm{D}_{\mathrm{MXTD}}$ behaved accordingly to $\Psi_{\text {stem }}$ on the days of sudden changes in $\mathrm{ET}_{\mathrm{o}}$. Likely this was due to the MXTD records being less affected than the $E_{\mathrm{p}}$ records by the fluctuating atmospheric demand on those days. Fernández et al. (2011b) concluded that the time course of $\mathrm{D}_{\text {MXTD }}$ was useful to indicate the onset, and severity, of water stress both in their DI60 and DI30 trees, which were under similar irrigation regimes than our 60RDI and 30RDI trees, respectively. Fernández et al. (2011c) worked with 12-year-old 'Arbequina' olive trees planted at $7 \mathrm{~m}$ $\times 6 \mathrm{~m}$, under low frequency deficit irrigation conditions, and found that $\mathrm{D}_{\text {MXTD }}$ was a sensitive and reliable water-stress indicator. In our high-density HOO, with a low soil water-holding capacity, either $\mathrm{D}_{E \mathrm{p}}$ or $\mathrm{D}_{\mathrm{MXTD}}$ can be used alone for reasonably precise assessments of water stress and water needs in the orchard.

The ZIM probes, together with the tailored telemetry system for data transfer to an internet server, showed to be user-friendly and robust. The system was able to monitor changes in the leaf water status inversely coupled to the turgor pressure. As for $D_{E p}$ and $\mathrm{D}_{\text {MXTD }}$, the information provided by the sensors, available in real-time, is of benefit for assessing water stress in commercial HOO. Still, more information is required on how to process the information derived from inverse $P_{\mathrm{p}}$ curves. Also important is to derive an appropriate index to schedule irrigation from $P_{\mathrm{p}}$ curves. Three promising indicators for the early detection of water stress have been described (Westhoff et al., 2009; Rüger et al., 2010): (i) the increase of the $P_{\mathrm{p}}$ peak values at noon, (ii) the increase of the recovery time of turgor pressure during the afternoon and (iii) the increase of the $P_{\mathrm{p}}$ night values. 
The usefulness of these indicators to schedule irrigation in $\mathrm{HOO}$ could be a matter for future research.

\section{CONCLUSIONS}

The three compared methods, based on SF, TDV and LT measurements were useful for an early assessment of water stress in HOO. Both $\mathrm{D}_{E \mathrm{p}}$ and $\mathrm{D}_{\mathrm{MXTD}}$ have a potential for high precision irrigation in HOO. The $P_{\mathrm{p}}$ outputs suggest that a useful index to schedule irrigation in HOO could be derived. The earliness, reliability and robustness of the three approaches are reasonably good, although the user must take into account limitations derived from the fundamentals of each method and from the physiological response of the plant to water demanding conditions.

\section{ACKNOWLEDGEMENTS}

This experiment was funded by the Spanish Ministry of Science and Innovation, research project AGL2009-11310/AGR. Thanks are due to the owners of Internacional Olivarera, S.A.U. (Interoliva), for allowing us to make the experiments in the Sanabria farm. Antonio Montero helped us with the field measurements. We also thank Silvia Seller, agronomist, and Juan Francisco Bernabé, foreman, for their technical assistance.

\section{Literature Cited}

Ben-Gal, A., Kool, D., Agam, N., van Halsema, G.E., Yermiyahu, U., Yafe, A., Presnov, E., Erel, R., Majdop, A., Zipori, I., Segal, E., Rüger, S., Zimmermann, U., Cohen, Y., Alchanatis, V. and Dag, A. 2010. Whole-tree water balance and indicators for short-term drought stress in non-bearing 'Barnea' olives. Agric. Water Manage. 98:124-133.

Chalmers, D.J., Mitchell, P.D. and van Heek, L. 1981. Control of peach tree growth and productivity by regulated water supply, tree density and summer pruning. J. Amer. Soc. Hort. Sci. 106:307-312.

Connor, D.J. and Fereres, E. 2005. The Physisology of adaptation and yield expression in olive. Hortic. Rev. 34:155-229.

Cuevas, M.V., Torres-Ruiz, J.M., Álvarez, R., Jiménez, M.D., Cuerva, J. and Fernández, J.E. 2010. Usefulness of trunk diameter variations for irrigation scheduling in a mature olive tree orchard. Agric. Water Manage. 97:1293-1302.

Ehrenberger, W., Sann, C., Rüger, S., Diaz-Espejo, A., Fernández, J.E., Sukhorukov, V., Zimmermann, U., 2011. Leaf patch clamp pressure probe measurements on olive leaves in the nearly turgorless state. Plant Biol., doi:10.1111/j.14388677.2011.00545.x

Fernández, J.E., Cuevas, M.V. 2010. Irrigation scheduling from stem diameter variations: a review. Agric. For. Meteorol. 150:135-151.

Fernández, J.E., Diaz-Espejo, A., Infante, J.M., Durán, P., Palomo, M.J., Chamorro, V., Girón, I.F. and Villagarcía, L. 2006. Water relations and gas exchange in olive trees under regulated deficit irrigation and partial rootzone drying. Plant Soil 284: 271-287.

Fernández, J.E., Green, S.R., Caspari, H.W., Diaz-Espejo, A. and Cuevas, M.V. 2008. The use of sap flow measurements for scheduling irrigation in olive, apple and Asian pear trees and in grapevines. Plant Soil 305:91-104. 
Fernández, J.E., Moreno, F., Martín-Palomo, M.J., Cuevas, M.V., Torres-Ruiz, J.M. and Moriana, A. 2011b. Combining sap flow and trunk diameter measurements to assess water needs in mature olive orchards. Environ. Exp. Bot. 72:330-338.

Fernández, J.E, Palomo, M.J., Díaz-Espejo, A., Clothier, B.E., Green, S.R., Girón, I.F. and Moreno, F. 2001. Heat-pulse measurements of sap flow in olives for automating irrigation: tests, root flow and diagnostics of water stress. Agric. Water Manage. 51:99-123.

Fernández, J.E., Rodriguez-Dominguez, C.M., Perez-Martin, A., Zimmermann, U., Rüger, S., Martín-Palomo, M.J., Torres-Ruiz, J.M., Cuevas, M.V., Sann, C. and Ehrenberger, W. 2011a. Online-monitoring of tree water stress in a hedgerow olive orchard using the leaf patch clamp pressure probe. Agric. Water Manage. 100:25-35.

Fernández, J.E., Torres-Ruiz, J.M., Diaz-Espejo, A., Montero, A., Álvarez, R., Jiménez, M.D., Cuerva, J. and Cuevas, M.V. 2011c. Use of maximum trunk diameter measurements to detect water stress in mature 'Arbequina' olive trees under deficit irrigation. Agric.Water Manage. 98:1813-1821.

Gómez-del-Campo, M., Centeno, A. and Connor, D.J. 2009. Yield determination in olive hedgerow orchards. I. Yield and profiles of yield components in north-south and east- west oriented hedgerows. Crop Pasture Sci. 60:434-442.

Granier, A. 1987. Evaluation of transpiration in a Douglas-fir stand by means of sap flow measurements. Tree Physiol. 3:309-320.

Green, S.R., Clothier, B.E. and Jardine, B. 2003. Theory and practical application of heatpulse to measure sap flow. Agron. J. 95:1371-1379.

Ortuño, M.F., Conejero, W., Moreno, F., Moriana, A., Intrigliolo, D.S., Biel, C., Mellisho, C.D., Pérez-Pastor, A., Domingo, R., Ruiz-Sánchez, M.C., Casadesus, J., Bonany, J. and Torrecillas, A. 2010. Could trunk diameter sensors be used in woody crops for irrigation scheduling? A review of current knowledge and future perspectives. Agric. Water Manage. 97:1-11.

Rius, X. and Lacarte, J.M. 2010. La revolución del olivar. El cultivo en seto, 340 pp.

Tognetti, R., Giovannelli, A., Lavini, A., Morelli, G., Fragnito, F. and d'Andria, R. 2009. Assessing environmental controls over conductances through the soil-plantatmosphere continuum in an experimental olive tree plantation of southern Italy. Agric. For. Meteorol. 149:1229-1243.

Vossen, P. 2007. Olive oil: History, production, and characteristics of the world's classic oils. HortScience 42(5):1093-1100.

Zimmermann, D., Reuss, R., Westhoff, M., Geßner, P., Bauer, W., Bamberg, E., Bentrup, F.-W., Zimmerman, U., 2008. A novel, non-invasive, online-monitoring, versatile and easy plant-based probe for measuring leaf water status. J. Exp. Bot. 59: 31573167. 


\section{Figures}

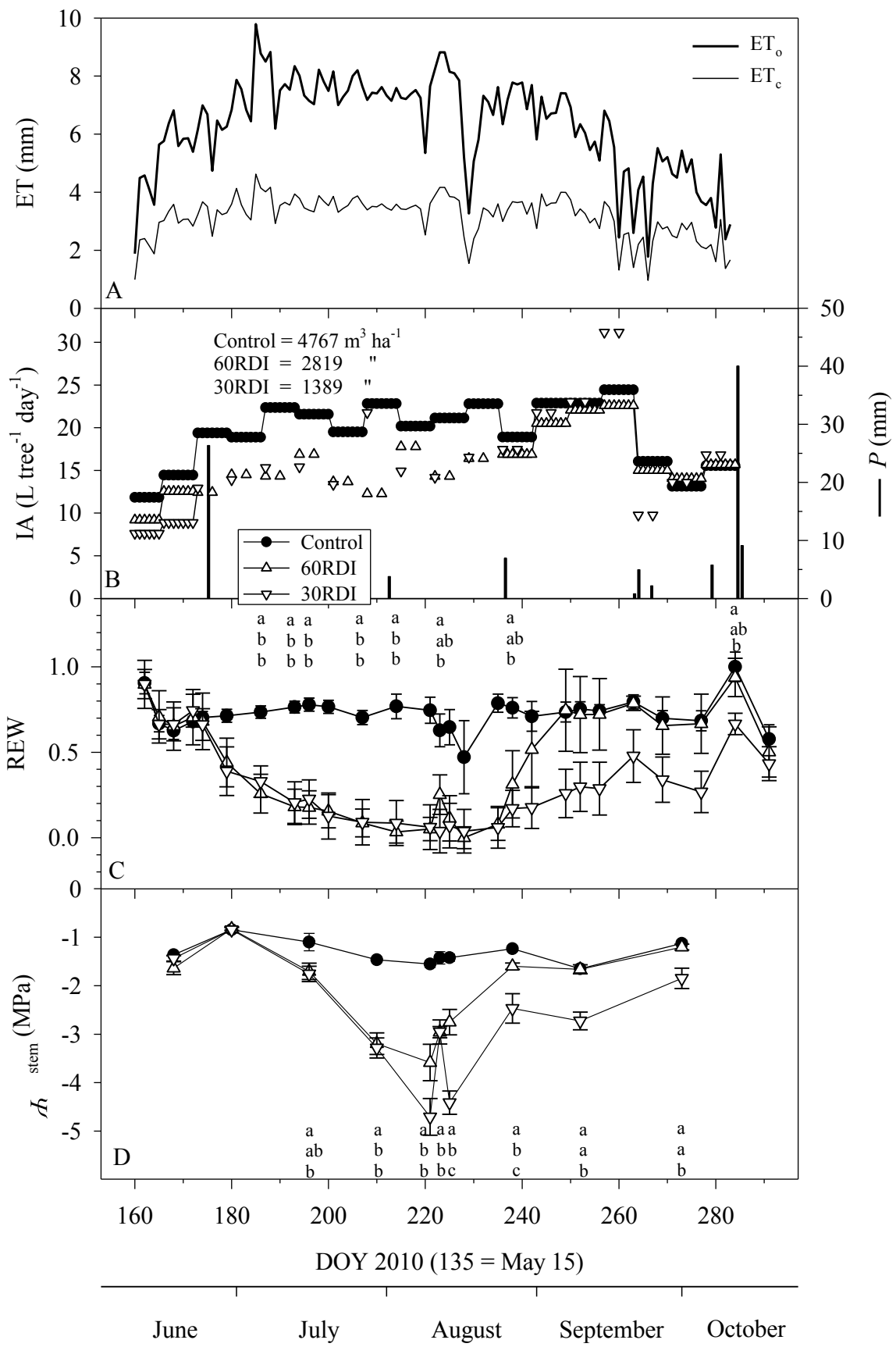

Fig. 1. Seasonal courses of $(\mathbf{A})$ the potential $\left(\mathrm{ET}_{\mathrm{o}}\right)$ and crop $\left(\mathrm{ET}_{\mathrm{c}}\right)$ evapotranspiration, $(\mathbf{B})$ the irrigation amounts (IA) supplied to each treatment and the collected precipitation $(P),(\mathbf{C})$ the relative extractable water $(\mathrm{REW})$, and $(\mathbf{D})$ the midday stem water potential $\left(\Psi_{\text {stem }}\right)$ measured on representative trees of each treatment during the experimental period $(n=8)$. Vertical bars represent \pm the standard error. In Figs. C and D, different letters indicate statistically significant difference; data sets without letters means no difference between treatments. DOY = day of year. 


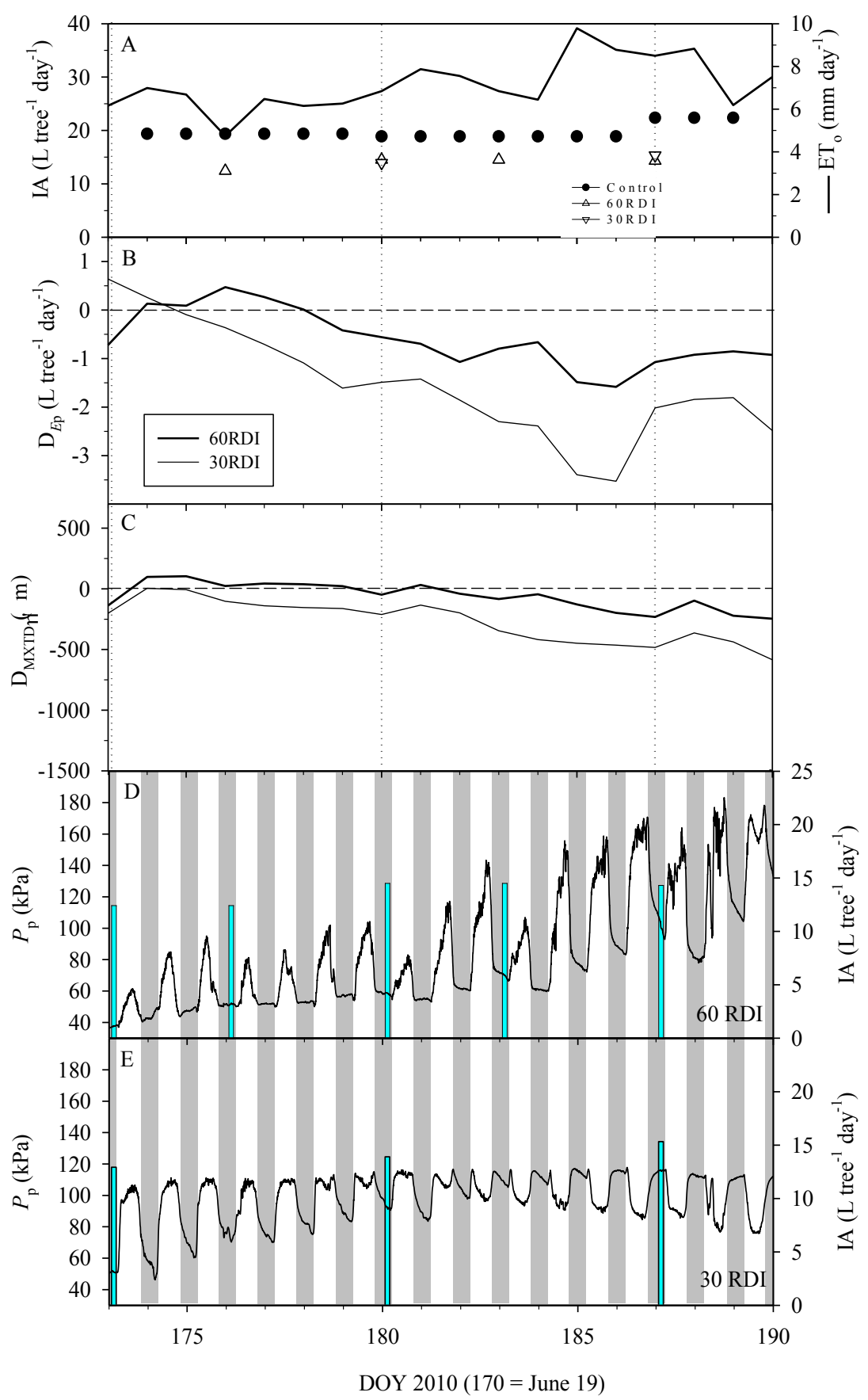

Fig. 2. Time course of the FAO56 Penman-Monteith potential evapotranspiration $\left(\mathrm{ET}_{\mathrm{o}}\right)$ and irrigation amounts (IA) supplied to the trees of each treatment (A), the daily difference between the average $E_{\mathrm{p}}$ values in each RDI treatment minus the average $E_{\mathrm{p}}$ values in the control treatment $\left(\mathrm{D}_{E \mathrm{p}}\right)(\mathbf{B})$, the daily difference between the average maximum trunk diameter (MXTD) values in each RDI treatment minus the average MXTD values in the control treatment $\left(\mathrm{D}_{\mathrm{MXTD}}\right)(\mathbf{C})$, and the changes of $P \mathrm{p}$ measured on east-oriented leaves of a 60RDI tree (D) and a 30 RDI tree (E). The $E_{\mathrm{p}}$ values were estimated from sap flow records. For $\mathrm{D}_{E \mathrm{p}}$ and $\mathrm{D}_{\mathrm{MXTD}}$, the shown values are the average of three trees per treatment recorded at the beginning of the water restriction period applied to the RDI treatments in midsummer. Also shown are the irrigation amounts (IA) supplied to the RDI trees (vertical bars in Figs. E and E). The gray bars represent the nocturnal periods. DOY = day of year. 


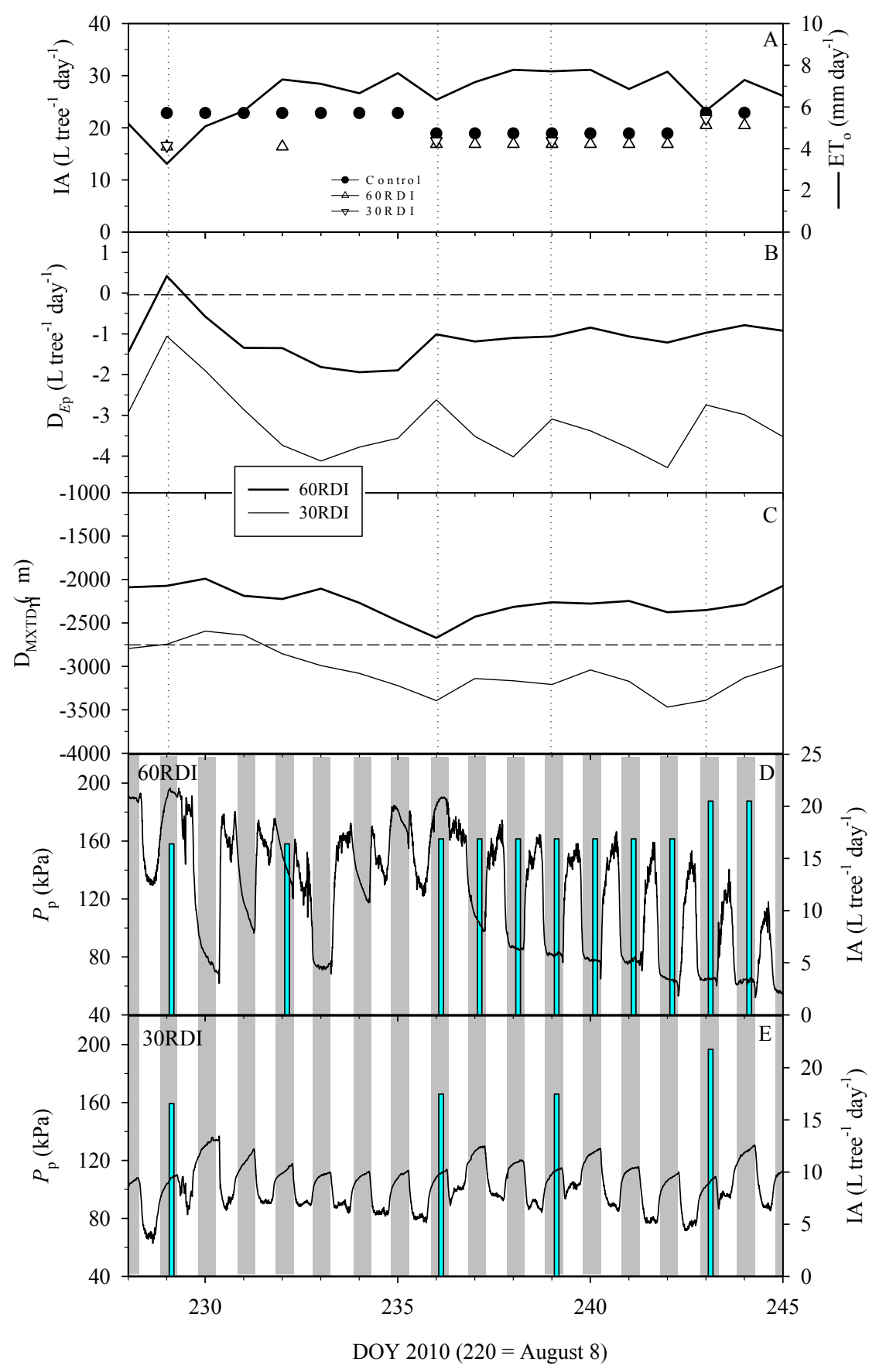

Fig. 3. Idem as Fig. 2, but for the period of recovery from water stress due to the increase in irrigation supplies from DOY 236. 